\title{
ECOLOGÍA URBANA Y CONTROL POBLACIONAL DE ANIMALES DOMÉSTICOS
}

\author{
Katiana Barbosa de ARRUDA ${ }^{\mathbf{1}}$; Gil Dutra FURTADO²; Daniel da Silva VIEIRA ${ }^{\mathbf{3}}$
}

\begin{abstract}
${ }^{1}$ Bacharela em Direito/Universidade Estadual da Paraíba (UEPB); Licenciada em Letras/UEPB. Mestra em Linguagens e Letramentos/UEPB. Mestra em Desenvolvimento e Meio Ambiente (PRODEMA)/Universidade Federal da Paraíba (UFPB), Brasil. E-mail: katianacazu@ hotmail.com

${ }^{2}$ Engenheiro Agrônomo/UFPB; Doutor em Psicobiologia/Universidade Federal do Rio Grande do Norte (UFRN); Agrônomo-Sócio da Cooperativa de Agronegócio (COOPAGRO), Brasil. E-mail: gdfurtado@hotmail.com

${ }^{3}$ Bacharel em Ecologia/UFPB, Mestre em Desenvolvimento e Meio Ambiente (PRODEMA)/UFPB, Doutorando em Ecologia Humana/Faculdade de Ciências Sociais e Humanas/Universidade Nova de Lisboa (FCSH/UNL), Portugal. E-mail: ecologodaniel@gmail.com
\end{abstract}

Resumen. Este trabajo tiene como objetivo presentar la importancia de la ecología urbana para la gestión ambiental y el control poblacional de animales domésticos, considerandos un problema de salud pública y una amenaza a la fauna nativa. Con la adopción de una gestión pública responsable, bien como la observación y el cuidado del medio ambiente en los centros urbanos, es posible hacer que las ciudades sean equilibradas y armónicas en beneficio de la convivencia de todos los animales, sean eles domésticos, silvestres o exóticos. Como metodología para esta investigación, ser realizó un levantamiento del referencial teórico.

Palabras clave: Etología animal; Comportamiento humano; Gestión ambiental; Salud pública.

\section{ECOLOGIA URBANA E CONTROLE POPULACIONAL DE ANIMAIS DOMÉSTICOS}

Resumo. Esse trabalho tem como objetivo apresentar a importância da ecologia urbana para a gestão ambiental e o controle populacional de animais domésticos, considerados um problema de saúde pública e uma ameaça à fauna nativa. Com a adoção de uma gestão pública responsável, bem como, a observância e o cuidado para com o meio ambiente nos centros urbanos, é possível tornar as cidades equilibradas e harmônicas em benefício do convívio de todos os animais, sejam eles domésticos, silvestres ou exóticos. Como metodologia para essa pesquisa, foi feito um levantamento do referencial teórico.

Palavras-chave: Etologia animal; Comportamento humano; Gestão ambiental; Saúde pública. 


\section{URBAN ECOLOGY AND POPULATION CONTROL OF DOMESTIC ANIMALS}

Abstract. This work aims to present the importance of urban ecology for environmental management and population control of domestic animals, considered a public health problem and a threat to native fauna. With the adoption of a responsible public management, as well as the observation and care of the environment in urban centers, it is possible to develop balanced and harmonious, searching the benefit of the coexistence of all animals, be they domestic, wild or exotic As a methodology for this research, it was carried out a survey of the theoretical referential.

Keywords: Animal ethology; Human behavior; Environmental management; Public health.

\section{EL PROCESO DE INDUSTRIALIZACIÓN Y LA POBLACIÓN DE ANIMALES CALLEJEROS}

En el periodo de la prehistoria, apenas los animales mayores como caballos, mamuts, rinocerontes, bisontes, jabalís, entre otros también de gran porte; eran retratados en las paredes de las cavernas. De acuerdo con Morris (1990), en el capítulo titulado "La Compañía Animal" del libro El Contrato Animal, los animales menores no eran temidos y por eso, después de devorados, no merecían ser recordados como resultado de grandes hazañas.

Para el autor, la relación de mayor proximidad y respeto para con los animales menores solo vino a ocurrir cuando el gato salvaje de Egipto fue domesticado para servir como destructor de plagas. Desde entonces, son muchas las especies tenidas como domésticas.

En Brasil, por ejemplo, existen legalmente cincuenta especies de animales domésticos, según la resolución No. 93 del 7 de julio de 1998, del "Instituto Brasileiro do Meio Ambiente e dos Recursos Naturais Renováveis" (IBAMA), entre ellos: equinos, caprinos, bovinos, porcinos, aves, así como perros y gatos; considerados por gran parte de la población, como los animales domésticos de mayor popularidad entre los brasileros (IBAMA, 1998).

Dicha resolución, también considera como animales de la fauna doméstica todos aquellos animales que pasaron por procesos tradicionales y/o por mejoramiento zootécnico, de manera que acabaron por adquirir características biológicas y comportamentales en estrecha dependencia con el ser humano, diferenciándose en su fenotipo de la especie silvestre que los originó.

En relación con la etimología de la palabra, el diccionario Michaelis (2017), define la palabra doméstico (originaria del latín domesticus) como casa. Se dice también del animal que vive en casa, en la compañía del ser humano y bajo su dominio, a fin de servir en el trabajo y 
proveerle sus productos. Es sinónimo de mansedumbre, animal manos, amansado por sucesivas generaciones.

Por otro lado Bechara (2003), entiende que "doméstica" se refiere a la especie animal y no necesariamente al animal en sí, pues mismo que un perro (Canis familiaris) o un gato (Felis catus) pasen a vagar libremente por las calles, jamás serán tomados como animales silvestres, teniendo en cuenta que ya fueron reconocidos y nombrados como animales domésticos.

A pesar de existir una resolución para reguladora sobre cuales animales pertenecen a la fauna doméstica, silvestre y exótica; no existe en el país una norma específica disciplinando la protección de los animales domésticos (diferente de la fauna silvestre protegida por la Ley Brasileña $\mathrm{n}^{\circ}$. 5.197/1967), disminuyendo así la posibilidad de invocar los diplomas genéricos de protección a los animales, a ejemplo de la "Constituição Federal de 1988" y/o a "Lei Federal de Crimes Ambientais”, Ley no. 9.605/1998 (BRASIL, 1988; 1998).

En esa perspectiva, la Organización Mundial de la Salud (OMS), estima que existió en 2017 una población de 30 millones de animales abandonados dentro del territorio brasilero, siendo 10 millones de gatos y 20 millones de perros.

En los centros urbanos se estima que existe un perro para cada cinco habitantes, siendo que $10 \%$ de esos animales se encuentran en situación de riesgo en las calles, ocasionando una serie de daños a los municipios y a la población, tales como: desorden urbano, daño al medio ambiente, polución visual, sobrepoblación de perros y gatos. Además de esas situaciones, preocupa la amenaza a la salud colectiva humana por la frecuencia y la exposición de la población a zoonosis (enfermedades transmisibles de animales para seres humanos), generada por el convivir con estos animales en estos índices de sobrepoblación y el abandono de los mismos.

Las zoonosis exponen la población humana a graves problemas de salud, principalmente por el riesgo de contraer estas enfermedades mediante la contaminación, por el contacto directo con esos animales o incluso con los fluidos corporales como heces, orina y/o saliva.

En ese sentido enfermedades como la rabia, hoy en día bajo control en Brasil por el éxito de las campañas de vacunación adoptada en el país desde el año 1973 por el Ministerio de Salud, puede presentar un problema grave de salud pública, especialmente a lo que concierne al rompimiento de la garantía de eficacia ofrecida por la cobertura del esquema de vacunación de estos animales. Además, la falta de control poblacional de perros y gatos en los centros urbanos, así como el manejo inapropiado de esos animales, han ocasionado la 
proliferación de organismos patógenos que exponen a otras zoonosis como la toxoplasmosis, la cual es muy peligrosa para gestantes, principalmente cuando ocurre en el primer trimestre de gestación.

Además de la rabia y la toxoplasmosis, Lima y Luna (2012) alertan que de las 1415 especies de organismos patogénicos prejudiciales para el ser humano ya encontrados, 65\% identificados como zoonosis, entre las cuales se destacan la leptospirosis, tuberculosis, leishmaniosis, brucelosis, teniasis, cisticercosis (LIMA; LUNA, 2012); todas ellas entre las zoonosis de mayor relevancia para la salud pública.

En Brasil, la rabia transmitida a través de la mordida de caninos contaminados con el virus, es una enfermedad fatal y cuesta a los cofres públicos un promedio de 17 millones de reales al año, solo con el tratamiento preventivo, teniendo en vista que es grande el número de personas atacadas por perros en ese país.

Todo ese caos ocasionado por la falta de control poblacional de los animales domésticos en los centros urbanos, conforme Santos (2013), puede ser visto como un reflejo de mala organización y ocupación del territorio urbano, sobre todo a partir de las de 1940 y 1980, cuando buena parte de la población humana brasilera dejó los centros rurales, pasando a vivir y a desarrollarse en las ciudades.

"El fuerte movimiento de urbanización que se verifica a partir de la II Guerra Mundial es contemporáneo de un fuerte crecimiento demográfico, resultado de una elevada natalidad y un descenso en la mortalidad, cuyas causas esenciales son los progresos sanitarios, la mejora relativa en los parámetros de vida y la propia urbanización” (SANTOS, 2013 p. 33).

Sin embargo, ese fenómeno no se dio de manera homogénea en todos los estados, de modo que la urbanización se hizo más acentuada en las regiones sur y el sudeste del país, las cuales pasaron a tener el espacio construido y reconstruido debido a la llegada de la población y de la mecanización de los territorios, regiones marcadas de tal modo, por el avance de la ciencia y la tecnología.

Además de eso, el modelo de desarrollo implementado en Brasil en esa época, incentivó el aparecimiento de lo que Santos (2014) denominó como "consumidor más que perfecto", subordinado a las nuevas necesidades de consumo creadas por la perspectiva de “milagro" económico, en el periodo de 1968 a 1973.

En ese sentido, los animales de estimación ganaron espacio en la lista de los bienes de consumo más deseados por los brasileros, debido a una serie de habilidades y utilidades 
reconocidas en esos animales. Sin embargo, es necesario que las medidas de control ya existentes acerca del adecuado manejo de animales domésticos, sean tomadas de modo a garantizar que la convivencia con los mismos, no se configure en un problema de salud pública.

\section{CARACTERÍSTICAS, COMPORTAMIENTO Y DOMESTICACIÓN DE PERROS Y GATOS}

El perro (Canis lupus familiaris) fue uno de los primeros animales a ser domesticado por el ser humano. Conocido por ser cuadrúpedo y digitígrado, a lo largo del tiempo ese animal asumió diversas funciones en la sociedad.

Existen indicios de que ya en la prehistoria, la relación entre hombre y perro ya se firmaba, con la ayuda de ese cánido en la cacería y en la guardia de los humanos. En el Egipto Antiguo, era estimado como animal sagrado, conocedor de secretos del otro mundo. En la Edad Media, los perros pasaron a ser animales mal vistos, pues muchos de ellos comían cadáveres humanos contaminados por diversas enfermedades, como la peste negra.

Mientras tanto, durante el Renacimiento (S. XIV - XVII), ese animal ganó la simpatía de la nobleza, que acostumbraba cuidar de esta especia con ahínco y prestigio, utilizándolos para la cacería y los deportes. En ese periodo, muchas razas fueron desarrolladas, consideradas un tesoro y símbolo de estatus conforme destacó Thomas (2010).

De esa manera, la familia de los cánidos pasó por diversas transformaciones oriundas de cruces y de manipulación genética, de modo que actualmente, posee gran variedad de razas y perfiles, agradando a todos los gustos y asumiendo diversas funciones en la sociedad: guarda, guía, terapia, compañía, entre otras (SANTOS, 2006).

En Brasil, los canes son animales muy bien aceptados. De acuerdo con la "Associação Brasileira da Indústria de Produtos para Animais de Estimação" (ABINPET), el país posee 52,2 millones de perros, quedando atrás apenas de los Estados Unidos - 74,2 millones, siendo que $40 \%$ se concentran en el sudeste (ABINPET, 2018).

En Sao Paulo, el perro es parte fundamental en el tratamiento y recuperación de niños con deficiencia y trastornos psiquiátricos. La llamada TAC (Terapia Asistida por Canes) es responsable por promover beneficios de orden psíquico, físico y social. "Los efectos sobre los aspectos emocionales y sociales son espontáneos y muchas veces inesperados. Pueden generar resultados apenas por la presencia del animal". (DOTTI, 2014, p. 30).

Santos (2006), entiende que entre las numerosas ventajas de utilizar los canes en el tratamiento de personas portadoras de necesidades especiales, está el hecho de que esos 
animales son conocidos por imprimir responsabilidad, hábitos de higiene, rutina, alimentación y entretenimiento a los pacientes.

Además, los perros son estimados por poseer los sentidos de la visión, audición y del olfato desarrollados, demostrando que pueden ser más sensibles que los humanos en ciertos aspectos como, localizar drogas y minas terrestres, ver en la oscuridad, escuchar con precisión al punto de saber el origen y dirección del sonido en centésimas de segundo y a una distancia cuatro veces superior que el ser humano, además de discernir con facilidad las palabras pronunciadas por su tutor (HOROWITZ, 2012).

Un ejemplo de esas habilidades de los canes es relatado en el libro El rastro de la onza de Felipe Sussekind, pintor y antropólogo que investigó la relación entre seres humanos, canes y onzas en el Pantanal.

Según ese autor, todas las onzas del Proyecto Onza-Social ${ }^{1}$ solo podrán ser capturadas y acompañadas con la ayuda de los canes, denominados como maestros o canes onzeros, teniendo en cuenta que olfatean, localizan y cercan los grandes felinos. De esta manera se vuelven imprescindibles para la conservación de las onzas pintada y parda, animales que se encuentran en estado de vulnerabilidad debido a la destrucción de su hábitat natural para la creación de ganado y, consecuentemente la caza depredadora (SUSSEKIND, 2014).

En ese sentido, los canes prestan un gran servicio al medio ambiente respecto al trabajo de conservación de la biodiversidad en el Pantanal.

Otro ejemplo de los beneficios que la convivencia con los canes trae, son los efectos de bienestar físico y emocional compartidos entre seres humanos y perros, también pueden ser vistos en la interacción con los gatos. La población de esos animales han aumentado en consonancia con las nuevas tendencias de la sociedad contemporánea (CAVALHEIRO, 2017).

De acuerdo con el autor, ese aumento en la preferencia por gatos revela mucho sobre los tiempos modernos. Los felinos dependen menos de los dueños, dan menos trabajo y son considerados animales de estimación ideales para quien vive en apartamento. Para ese autor, la gran diferencia entre perros y gatos es que estos (los gatos) no son hipersociales, pudiendo generar preconcepto en relación al comportamiento presentado.

\footnotetext{
1 "Ese proyecto fue una experiencia pionera en Brasil, creada con el objetivo de evaluar el impacto económico y social de la depredación de ganado por parte de las onzas pintadas y onzas pardas en la región del Pantanal del Río Negro, Miranda y Aquidauana. Un total de once propiedades rurales se asociaron al proyecto, abarcando un área superior a 280.514 hectáreas donde 55.000 cabezas de ganado son criadas. En la asociación establecida, el "Projeto Onça-Social" compensó financieramente a los ganaderos por cada cabeza de ganado abatida por las onzas pintadas o las onzas pardas. En contrapartida, los ganaderos se comprometían a no abatir en ninguna circunstancia, las onzas presentes en sus propiedades". Disponible en: http://www.jaguar.org.br/pt/projetos/projeto-onca-social/index.html.
} 
Sin embargo, eso no quiere decir que los gatos sean criaturas solitarias y autosuficientes. Ellos poseen necesidades relacionadas a su salud y bienestar, como refiere Grandin (2010, p. 71), afirmando que "no puede usarse la aprobación social para adiestrar un gato, y los gatos no se domestican conforme a la relación del dueño, como los perros hacen algunas veces. Los canes sirven a las personas, pero las personas sirven a los gatos”. De este modo, queda evidente que el manejo y/o adiestramiento de canes y gatos requiere un cuidado diferenciado adecuado para cada animal, o sea, perro o gato. De esta manera, se puede decir que la inteligencia o capacidad de aprendizaje de los gatos no puede ser evaluada como mayor o menor que la de los perros.

Sin embargo, autores como Piedade (2013, p.78) manifiesta que "al testar sus habilidades de aprendizaje (de los canes y gatos) es preciso considerar las diferencias entre los sentidos y las capacidades motoras de los animales y su predisposición para ciertos comportamientos". Para el autor, cuando se trata de comparar el comportamiento y aprendizaje de especies tan diferencias como perros y gatos, el trabajo puede tornarse bastante difícil, si esas diferencias no son consideradas.

A pesar de que el gato doméstico Felis silvestres catus es uno de los animales de estimación más populares del mundo, poco se sabe sobre el origen de su domesticación. Perteneciente a la familia de los felinos, es considerado una especie poli típica, o sea, originada de algunas otras especies cruzadas entre sí, la Felis silvestres lybica (África), Felis silvestres (Europa), Felis silvestres ornata (Asia central), de acuerdo a la explicación de Genaro (2015).

De acuerdo con Grandin (2010), vestigios arqueológicos sugieren que, al contrario de lo que ocurrió con la domesticación del ganado (Bovinae) y del perro, el gato puede haber iniciado la aproximación con el ser humano por voluntad propia, alimentándose de los ratones que infestaban la agricultura. Tal vez por eso, durante la edad media hayan sido criados en casa para combatir ratones y ratas, considerados impuros y sucios conforme Thomas (2010).

A pesar de todo misterio que envuelve la domesticación de los gatos, esos animales como los canes, han vagado por las calles de Brasil, siendo denominados de animales errantes y/o domésticos. Estos animales han sido muchas veces descuidados por sus propios guardianes o simplemente largados a su propia suerte en los centros urbanos principalmente (CAMPOS, 2004).

Frente a tal problema y procurando la salud y el bienestar de la población humana, teniendo en vista que esos animales son fuertes candidatos a huéspedes y transmisores de muchas enfermedades, algunos municipios brasileros han providenciados leyes e instalado 
unidades de prevención y control poblacional de animales callejeros, los conocidos Centros de Control de Zoonosis (CCZs).

Sin embargo, todavía no existen políticas públicas efectivas que puedan resolver el problema de la sobrepoblación de canes y gatos, de modo que el ecosistema urbano se encuentra bastante amenazado.

\section{IMPORTANCIA DE LA ECOLOGÍA URBANA PARA EL EQUILIBRIO DE LA FAUNA DOMÉSTICA Y SILVESTRE}

El primer concepto sobre ecología fue acuñado por Heinrich Haeckel, biólogo y médico alemán en 1886, en su obra Morfología General de los Seres Vivos. El término viene del griego oikos (casa) y logia/logos (estudio), indicando una relación de comprensión a respecto de nuestro medio físico, o sea, las plantas, los animales y el medio ambiente natural.

De acuerdo con el diccionario de símbolos de Chevalier y Gheerbrant (2009), la palabra Eco, fue concebida como un atributo al grande dios catoniano: el jaguar, dios de las fuerzas internas, de la tierra, del sol, las montañas y de los animales salvajes.

Tales definiciones nos llevan a creer que la ecología de manera general, se preocupa sobre todo con los aspectos físicos, químicos o físico-químicos ocurridos en la naturaleza; es decir, con los factores abióticos que puede decirse siempre estuvo ligada al ramo de la Biología.

Sin embargo, con el despertar de la consciencia ecológica ocurrido a mediados de la década de 1960, así como las manifestaciones en pro del medio ambiente que vienen multiplicándose por todo Brasil, junto con eventos, simposios y movimientos realizados sobre el tema. La palabra ecología pasó a tener algunas connotaciones bastante amplias, incluyendo movimientos sociales, intelectuales, artísticos y políticos; asumiendo de esa forma un amplio rol de significados, construido por diversas ciencias.

Surgieron por lo tanto, denominaciones como ecología humana, ecología social, ecología política, Ecología profunda e incluso Ecología Interior. Para Milaré (2014), esas ramificaciones tienden a especificar mejor el papel y la responsabilidad de las personas con el medio ambiente, de forma que tanto el ambiente natural como el ambiente social puedan estar relacionados.

En ese sentido la Ecología Urbana también gana destaque, una nueva rama de la Ecología, que se justifica debido a la necesidad de entender los sistemas naturales ocurridos en las áreas urbanas de manera específica. 
Incluso porque en deterioro a todos los factores negativos ocurridos en función del crecimiento de las áreas urbanas, como la pérdida de los espacios naturales, de la biodiversidad, la mala distribución de renta, la falta de saneamiento básico y de planeamiento de las viviendas, entre otros problemas encontrados en las ciudades; todavía así, la zona urbana puede ser considerada el hábitat natural de muchas especies animales, incluyendo la fauna doméstica, silvestre y exótica (NUNES, 2017).

De acuerdo con el autor, dependiendo de la cantidad e de la calidad de los hábitats disponibles en los centros urbanos, las ciudades pueden atraer una cantidad significativa de animales silvestres. De esa manera, aves, reptiles y muchos mamíferos pueden encontrar en las ciudades un excelente refugio.

De otro modo, esos animales enfrentan en los centros urbanos una serie de dificultades de supervivencia, incluidas la polución, la deforestación, especies exóticas invasoras, malos tratos y la depredación por otros animales (los domésticos por ejemplo). Esta última amenaza viene constituyéndose con el aumento del número de canes y gatos errantes ${ }^{2}$ en el país (NUNES, 2017).

Algunas investigaciones (por ejemplo CAMPOS, 2004; RANGEL; NEIVA, 2013) ya han comprobado que la presencia de animales domésticos en áreas de protección ambiental como la mata atlántica y los parques forestales por ejemplo, puede generar un desequilibrio y la extinción de especies nativas.

Entre los años 2005 y 2012, fueron registradas 36 denuncias de perros depredando animales silvestres en el Jardín Botánico de Rio de Janeiro, de acuerdo a las fichas de registro de rescate de animales silvestres, el equivalente a $10 \%$ de todos los animales recogidos por injuria, de acuerdo con Rangel y Neiva (2013).

Según el muestreo de esos datos, los mamíferos estaban entre las especies más afectadas, sin embargo fueron rescatados también algunas aves y reptiles, algunos heridos y otros ya fallecidos. Gran cantidad de los animales lesionados también fue encontrada en un fragmento urbano de la floresta atlántica, en la región sudeste del país. Fueron 46 corazas de animales encontradas a lo largo de 44 meses según Galetti y Sazima (2006).

En este caso, los perros también fueron identificados como los principales causantes de transmisión de enfermedades, estrés, persecución y muerte de animales nativos. Mientras tanto, los gatos han sido responsabilizados por la pérdida de 2,4 billones de aves y 12,3 billones de mamíferos por año (GALETTI; SAZIMA, 2006). Estos datos ubica los felinos

\footnotetext{
${ }^{2}$ Término utilizado para designar el animal que anda sin destino, que vaga perdido o desorientado.
} 
como la segunda mayor causa de extinción de especies del planeta. Aunque sea un número elevado, es comprensible teniendo en cuenta la falta de políticas públicas, la sobrepoblación de animales errantes y la mala gestión de las ciudades en Brasil y en algunos países del mundo.

En un estudio realizado en los Pirineos Franceses en el sudoeste europeo, se constató que $91 \%$ de las depredaciones ocasionadas a los ovinos eran causadas por canes feroces, mientras que el 9\% restante fueron atribuidos a osos (YOUNG et al., 2011). Estos datos demuestran que los perros errantes pueden afectar el equilibrio de muchas especies animales, de modo que la salida muchas veces encontrada para el control de estos animales, es su erradicación.

Sin embargo, es importante mencionar que canes y gatos también sufren una serie de abusos en los centros urbanos, víctimas de maltratos, accidentes, hambre, sed, miedo, tristeza, además de una serie de enfermedades. Por eso, la importancia de pensar en una optimización de instrumentos utilizados para gestionar las ciudades y por ende el medio ambiente, es a través de la prevención, de la salud pública y de la protección de los bienes ambientales (fauna doméstica y silvestre).

De acuerdo con Silva (2015), la sociedad, los poderes públicos, las entidades de acogida para animales (Canis Públicos y Centros de Control de Zoonosis, estando está última ligada también a la salud humana); deben pensar en un plan de gestión ambiental que tenga como objetivo la capacitación de los agentes públicos, el control y la prevención sanitarioambiental, la preservación del medio ambiente y el bienestar de los animales domésticos.

Además, cabe al Poder Público y a la colectividad de acuerdo a los preceptos de la Constitución Federal Brasilera de 1988 (BRASIL, 1988), cuidar del medio ambiente, actuando según los principios de la prevención y de la precaución, con pericia y cautela para evitar posibles daños materiales y morales, pues un daño causado al medio ambiente "transporta la entidad preservada de un estado aceptable para otro estado, incompatible con los intereses de la sociedad" (TOCCHETTO, 2014, p. 272).

En ese sentido, la ecología urbana se presenta como una rama de la ecología capaz de suscitar soluciones viables, teniendo en cuenta que se preocupa con la interacción entre las personas, animales y plantas dentro de las áreas urbanas, tratando las ciudades como verdaderos ecosistemas y llevando en consideración todas las formas de vida, buscando maneras de administrar mejor el espacio público y tornar los ambientes sostenibles.

La influencia del hombre sobre la naturaleza "está tan naturalizada que es muy difícil encontrar un ambiente que todavía no esté afectado por actividad humana" (BEGON, 2007, p. 
2). En ese sentido, no hay como eximirse de responsabilidad para con los ambientes construidos, puesto que es nuestro deber prevenir las consecuencias y velar por un futuro sostenible, lanzando mano del conocimiento de la ciencia y de las tecnologías ya alcanzadas.

De esa forma, además de medidas prácticas como la prevención de la salud pública, vacunación, esterilización, control de comercio de animales; mencionada por Santana y Oliveira (2008), se hace necesario una mayor consciencia y sensibilización de la población a través de campañas de educación ambiental.

Cabe resaltar que los animales poseen derechos intrínsecos, siendo el principal de ellos su derecho a la vida, como seres dotados de sensibilidades y necesidades que merecen todo el respeto y cuidado por parte de los seres humanos. Ante ello, el artículo 225, VII de la Constitución Federal del Brasil de 1988, condena en la forma de la Ley, las prácticas que coloquen en riesgo o que sometan los animales a crueldad. Y a pesar de que la carta magna de 1988 no específica ni defina un rol de prácticas crueles cometidas a los animales, la Ley de crímenes ambientales "Ley 9605/98” (BRASIL, 2018) en su artículo 32, penaliza los actos de abuso y maltratos cometidos contra los animales, incluso los domésticos o domesticados.

Por lo tanto, así se trate de canes y gatos errantes, se debe pensar en acciones que puedan solucionar los problemas causados por esos animales, por ende no sin antes entrar en las cuestiones éticas y de bienestar animal, especialmente tratándose de animales de compañía cuyo comportamiento es capaz de decir mucho sobre los seres humanos, principales responsables por el cuidado y protección de esos animales.

\section{AGRADECIMENTOS}

Os autores agradecem ao apoio institucional do Programa de Pós-Graduação em Desenvolvimento e Meio Ambiente (PRODEMA) da Universidade Federal da Paraíba.

\section{REFERENCIAS}

ASSOCIAÇÃO BRASILEIRA DA INDÚSTRIA DE PRODUTOS PARA ANIMAIS DE ESTIMAÇÃO (ABINPET). Setor pet chega a R\$ 18 bilhões em 2015, mas não sem os efeitos da crise. 2018. Disponível em: <http://abinpet.org.br/site/setor-pet-chega-a-r-18bilhoes-em-2015-mas-nao-sem-os-efeitos-da-crise/>. Acesso em 5 jul. 2018.

BECHARA, E. Língua e linguagem. Rio de Janeiro: Editora da Universidade do Estado do Rio de Janeiro, 2003. 
BEGON, M. Ecologia: de indivíduos a ecossistema. Tradução de Adriano Sanches Melo et al. Porto Alegre: Artmed, 2007.

BRASIL. Constituição (1988). Constituição da República Federativa do Brasil. Brasília, DF: Senado Federal: Centro Gráfico, 1988.

BRASIL. Lei no 9.605, de 12 de fevereiro de 1998. Lei de Crimes Ambientais. Legislação federal. 2018. Disponível em: <http://www.planalto.gov.br/ccivil_03/leis/L9605.htm>. Acesso em: 10 jul. 2018.

CAMPOS, C.B. Impacto de cães (Canis familiaris) e Gatos (Felis catus) errantes sobre a fauna silvestre em ambiente peri-urbano. $71 \mathrm{f}$. Dissertação (Mestrado em Ecologia de Agroecossistemas)-Escola Superior de Agricultura "Luiz de Queiroz", Universidade de São Paulo. 2004.

CAVAlHEIRO, P. População de gatos cresce o dobro no Brasil em relação a de cães. Disponível em: http://g1.globo.com/hora1/noticia/2015/04/populacao-de-gatos-cresce-odobro-em-relacao-de-caes-no-brasil.html. Acesso em: 9 abr. 2017.

CHEVAliER, J.; GHEERBRANT, A. Dicionário de símbolos: mitos, sonhos, costumes, gestos, formas, figuras, cores, números. Tradução Vera da Costa e Silva et al. Rio de janeiro: J. Olympio, 2009.

DOTTI, J. Terapia e animais. São Paulo: Livrus, 2014.

GALETTI, M.; SAZIMA, I. Impactos de cães ferais em um fragmento urbano de Floresta Atlântica no sudeste do Brasil. Natureza \& Conservação, v. 4, n. 1, p. 58-63, 2006.

GENARO, G. Gato doméstico: comportamento e clínica veterinária. Disponível em: http://gelsongenaro.com.br/pdf/ETOLOGIA/MEDVEP2005.pdf. Acesso em: 5 abr. 2017.

GRANDIN, T. O bem-estar dos animais: proposta de uma vida melhor para todos os bichos. Tradução Angela Lobo de Andrade. Rio de Janeiro: Rocco, 2010. 
HOROWITZ, A. A cabeça do cachorro. Tradução de Lourdes Sette. Rio de Janeiro, 2012.

INSTITUTO BRASILEIRO DO MEIO AMBIENTE E DOS RECURSOS NATURAIS RENOVÁVEIS (IBAMA). Portaria n⿳ 93, de 7 de julho de 1998. Importação e exportação fauna silvestre, 1998. Disponível em: 〈http://www.ibama.gov.br>. Acesso em: 23 jul. 2018.

LIMA, A.F.M.; LUNA, S.P.L. Algumas causas e consequências da superpopulação canina e felina: acaso ou descaso? Revista Educação Continuada em Medicina Veterinária e Zootecnia do CRMV-SP, v. 10, n. 1, p. 32-38, 2012.

MICHAELIS. Moderno dicionário da língua portuguesa. São Paulo: Editora Melhoramentos, 2017.

MILARÉ, E. Direito do Ambiente. São Paulo: Editora Revista dos Tribunais, 2014.

MORRIS, D. O contrato animal. Tradução Lucia Simonini. Rio de janeiro: Record, 1990.

NUNES, O.C. O comércio clandestino e a saúde dos animais silvestres. Informe Vet, Salvador, p. 8, 2017.

PIEDADE, H.M. Caderno de educação ambiental: fauna urbana, n. 17, v. 1. São Paulo: Secretaria do Meio Ambiente, 2013.

RANGEL, C.H.; NEIVA, C.H.M.B. Predação de vertebrados por cães Canis lupus familiaris (Mammalia: Carnivora) no Jardim Botânico do Rio de Janeiro, RJ, Brasil. Biodiversidade brasileira, Brasília, v. 3, n. 2, p. 261-269, 2013.

SANTANA, L.R.; OLIVEIRA, T.P. Guarda responsável e dignidade dos animais. 2008. Disponível em: <http://www.abolicionismoanimal.org.br/artigos/guarda_responsavel_e_dignidade_dos_anim ais.pdf>. Acesso em: 9 jul. 2018.

SANTOS, K.C.P.T. Terapia assistida por animais: uma experiência além da ciência. São Paulo: Paulinas, 2006. 
SANTOS, M. A urbanização brasileira. São Paulo: Editora da Universidade de São Paulo, 2013.

SANTOS, M. O espaço cidadão. São Paulo: Editora da Universidade de São Paulo, 2014.

SILVA, N.G. Proposta de um sistema de gestão ambiental adaptado a canis municipais. In: CONGRESSO BRASILEIRO DE GESTÃO AMBIENTAL, 6., 2015, Porto Alegre. Resumos... Porto Alegre, 2015, p. 1-11.

SUSSEKIND, F. O rastro da onça: relações entre humanos e animais no Pantanal. Rio De Janeiro: 7Letras, 2014.

THOMAS, K. O homem e o mundo natural: mudanças de atitude entre homens e animais (1500-1800). Tradução de João Roberto Martins Filho. São Paulo: Companhia das Letras, 2010.

TOCCHETTO, D. Perícia Ambiental Criminal. 3 ed. São Paulo: Millennium Editora, 2014.

YOUNG, J.K.; OLSON, K.A.; READING, R.P.; AMGALANBAATAR, S.; BERGER, J. Is wildlife going to the dogs? Impacts of feral and free-roaming dogs on wildlife populations. BioScience, Cary, v. 61, n. 2, p. 125-132, 2011. 